\title{
Susceptibility testing of Neisseria gonorrhoeae to penicillin and spectinomycin in a diagnostic laboratory
}

\author{
M J GILL, C A ISON \\ From the Department of Medical Microbiology, Wright-Fleming Institute, St Mary's Hospital Medical School, \\ London
}

SUMMARY Agar dilution breakpoint susceptibility testing using GC, DST, and proteose agars, was performed on consecutive clinical isolates of non-penicillinase producing Neisseria gonorrhoeae to examine the feasibility of using such a system in a diagnostic laboratory. The incidence and level of resistance to penicillin and spectinomycin was also assessed. On DST medium 93 of $200(46.5 \%)$ of isolates were of intermediate resistance to penicillin (MIC 0.12-0.5 mg/l) and 21 of $200(10.5 \%)$ were resistant to penicillin (MIC $\geqslant 1.0 \mathrm{mg} / \mathrm{l})$. Ninety two of $200(46 \%)$ of isolates had an MIC to spectinomycin of $32 \mathrm{mg} / \mathrm{l}$ on DST agar. Isolates seemed to be more resistant when tested on the two other media.

The methods used in this study could be applied in a routine diagnostic laboratory for immediate clinical benefit and long term epidemiological studies. To enable direct comparisons to be made between populations at different centres, however, methods for gonococcal susceptibility testing need to be standardised.

The retrospective antibiotic susceptibility testing of Neisseria gonorrhoeae used to be regarded as of limited value as most patients would already have been successfully treated empirically on the basis of a Gram stain. The long standing problem of chromosomal resistance to penicillin ${ }^{\prime}$ was overcome by using increased doses of penicillin, but the increased incidence of clinically important chromosomal resistance to penicillin ${ }^{23}$ and resistance due to $\beta$-lactamase production $^{4}$ requires the use of other antibiotics. Unfortunately, gonococci are now showing resistance to appropriate alternatives, such as spectinomycin ${ }^{56}$ and tetracycline. ${ }^{7}$ There are no rapid tests for nonenzymic gonococcal resistance to $\beta$-lactam antibiotics. These changing patterns of resistance therefore necessitate continuous surveillance by susceptibility testing to enable rational empirical treatment to be planned in different geographical areas.

In this study we examined the feasibility of using agar dilution breakpoint susceptibility testing in a diagnostic laboratory. This method of susceptibility testing determines the presence or absence of growth of an isolate on agar containing antibiotic. The use of a few select antibiotic concentrations, rather than the full range of concentrations used in conventional minimum inhibitory concentration (MIC) determina-

Accepted for publication 7 April 1988 tion, enables isolates to be allocated to susceptibility categories. Each antibiotic concentration used in this technique is known as a "breakpoint".

We used agar dilution breakpoint susceptibility testing to assess the incidence and level of resistance to spectinomycin, the first line treatment of uncomplicated anogenital gonorrhoea at the Praed Street clinic for sexually transmitted diseases, and to penicillin. Isolates were also auxotyped and serotyped to provide further epidemiological information.

\section{Material and methods}

\section{STRAINS}

During August to October 1986, 300 clinical isolates of Neisseria gonorrhoeae were collected. Antibiotic susceptibility testing was performed on the day of isolation. The first 200 consecutive isolates were tested only for their antibiotic susceptibility. The subsequent 100 consecutive isolates were also auxotyped and serotyped. Although these strains were almost entirely from the Praed Street clinic for sexually transmitted diseases, London, a small number came from gynaecology outpatient clinics or general practitioners' patients. They were isolated on GC agar base (BBL) supplemented with $1 \%$ IsoVitaleX. This medium also contained amphotericin B $(1.5 \mathrm{mg} / \mathrm{l})$, colistin $(1000 \mu \mathrm{g} /$ 1), trimethoprim $(5 \mathrm{mg} / \mathrm{l})$ and vancomycin $(3 \mathrm{mg} / \mathrm{l})$. 
The primary isolation plates were incubated at $36^{\circ} \mathrm{C}$ in $6 \%$ carbon dioxide for 48 hours. Isolates were identified as Neisseria gonorrhoeae by Gram stain, oxidase reaction, and the utilisation of glucose, but not of maltose, sucrose or lactose. Penicillinase producing isolates were detected by using the chromogenic cephalosporin Nitrocefin (Oxoid). No penicillinase producing gonococci were included in this study.

The five WHO control strains A-E (supplied by Dr AE Jephcott, Gonococcal Reference Laboratory, Bristol), four control strains obtained from the Centers for Disease Control (CDC, Atlanta, supplied by Dr JS Knapp), and the six strains from the United Kingdom national external quality assessment scheme (UKNEQAS) of September $1986^{8}$ were also tested.

\section{SUSCEPTIBILITY TESTING}

Three media were used for susceptibility testing: DST agar $(36 \mathrm{~g} / \mathrm{l} ;$ Oxoid) supplemented with $5 \%$ lysed horse blood and $1 \%$ IsoVitaleX; GC agar base $(36 \mathrm{~g} / \mathrm{l}$; Difco) with $1 \%$ IsoVitaleX; Proteose No 3 agar (45 g/1; Difco) supplemented with $1 \%$ haemoglobin (Difco) and $1 \%$ IsoVitaleX.

The antibiotics used were in the form of Adatabs (Mast Laboratories). Fresh solutions were made before pouring each set of plates. Initially media were stored for up to 10 days at $4^{\circ} \mathrm{C}$ in sealed plastic bags and the susceptibility of control strains tested daily. Subsequently media were stored for up to seven days at $4^{\circ} \mathrm{C}$.

Media contained penicillin at concentrations of 0.06 $\mathrm{mg} / \mathrm{l}, 0.5 \mathrm{mg} / \mathrm{l}$, or $1 \mathrm{mg} / \mathrm{l}$ and spectinomycin at concentrations of $16 \mathrm{mg} / 1,32 \mathrm{mg} / \mathrm{l}$, or $64 \mathrm{mg} / \mathrm{l}$. The concentration of penicillin incorporated into the medium enabled strains to be categorised as "sensitive" (MIC $\leqslant 0.06 \mathrm{mg} / \mathrm{l}$ ), of "intermediate resistance" (MIC 0.12-0.5 mg/l), or "resistant" (MIC $\geqslant 1.0$ $\mathrm{mg} / \mathrm{l}){ }^{9}$

Organisms were suspended in saline directly from primary isolation plates and their concentration corrected by measurement of optical density. Media were inoculated with a multipoint inoculator (Denley) to give a final inoculum of about $10^{5}$ colony forming units (cfu).

The inoculated plates were incubated at $36^{\circ} \mathrm{C}$ in $6 \%$ carbon dioxide and were read at both 24 and 48 hours. The MIC of antibiotic giving complete inhibition of growth was taken as the end point.

\section{SEROTYPING}

Serotyping was performed using a series of monoclonal antibodies raised to different epitopes of protein I. Boiled suspensions of isolates were tested by coagglutination with a panel of 12 antibodies (Syva). The patterns of agglutination enabled isolates to be classified into serovars: ${ }^{10}$

\section{AUXOTYPING}

The nutritional requirements of isolates were determined on the defined media of Copley and Egglestone." The presence or absence of growth was noted after 24 hours' incubation.

Data were analysed using the Statistical Package for Social Sciences (SPSS). The significance of differences in distributions was determined using the Mann-Whitney $U$ test for significance between two media.

\section{Results}

Of the 200 isolates initially examined, $86(43 \%)$ were from women, $107(53.5 \%)$ were from the urethra of men, and seven (3.5\%) were from the rectum of men. The further 100 isolates tested comprised $46(46 \%)$ from women, $52(52 \%)$ from the urethra of men, and two $(2 \%)$ from the rectum of men.

In the 100 consecutive isolates auxotyped we found that $38(38 \%)$ were prototrophic, $26(26 \%)$ were arginine-, hypoxanthine-, and uracil-requiring (AHU) and $19(19 \%)$ were proline-requiring (Pro). The remaining $17(17 \%)$ of isolates were of six other auxotypes. We detected 18 serovars in the 100 isolates serotyped. The most common of these were PrIB-3 $(36 / 100 ; 36 \%)$, PrIA-10 (15/100; 15\%), and PrIA-2 $(12 / 100 ; 12 \%)$. A total of 37 auxotype/serovar (A/S) classes were thus present in this population.

\section{ANTIBIOTIC SUSCEPTIBILITY DISTRIBUTIONS}

Table 1 shows the distribution of penicillin susceptibility among 200 isolates of Neisseria gonorrhoeae from clinical specimens, when breakpoints were determined on DST agar with lysed blood and IsoVitaleX, or on GC agar with IsoVitaleX. Isolates seemed to be more resistant on GC agar when compared with DST agar. While the difference in frequency distribution did not reach significance

Table 1 Susceptibility of 200 clinical isolates of Neisseria gonorrhoeae to penicillin and spectinomycin measured on $G C$ and DST agars by agar dilution breakpoint susceptibility testing

\begin{tabular}{|c|c|c|}
\hline \multirow{3}{*}{$\begin{array}{l}\text { Susceptibility } \\
\text { category }\end{array}$} & \multicolumn{2}{|c|}{$\begin{array}{l}\text { No of strains in each } \\
\text { susceptibility category } \\
\text { (\%) }\end{array}$} \\
\hline & \multicolumn{2}{|l|}{ Tested on } \\
\hline & DST agar & GC agar \\
\hline $\begin{array}{l}\text { Penicillin: } \\
\text { "Sensitive" MIC } \leqslant 0.06 \mathrm{mg} / 1 \\
\text { "Intermediate" MIC } 0.12-0.5 \mathrm{mg} / 1 \\
\text { "Resistant" MIC } \geqslant 1.0 \mathrm{mg} / \mathrm{l}\end{array}$ & $\begin{array}{l}86(43 \cdot 0) \\
93(46 \cdot 5) \\
21(10 \cdot 5)\end{array}$ & $\begin{array}{l}77(38 \cdot 5) \\
93(46 \cdot 5) \\
30(15 \cdot 0)\end{array}$ \\
\hline $\begin{array}{l}\text { Spectinomycin: } \\
\text { MIC } \leqslant 16 \mathrm{mg} / 1 \\
\text { MIC } 32 \mathrm{mg} / 1 \\
\text { MIC } 64 \mathrm{mg} / \mathrm{l}\end{array}$ & $\begin{array}{c}107(53 \cdot 5) \\
92(46 \cdot 0) \\
1(0 \cdot 5)\end{array}$ & $\begin{array}{r}44(22 \cdot 0) \\
155(77 \cdot 5) \\
1(0 \cdot 5)\end{array}$ \\
\hline
\end{tabular}


( $p>0.05$ ), it may reach significance if larger numbers are used.

We saw a similar effect when the spectinomycin susceptibility of 200 isolates was measured (table 1). These apparently striking differences may only represent a change of one doubling dilution, which would be within the accepted experimental error for this technique; but no isolate seemed to be more resistant on DST than on GC medium.

The susceptibility of a further 100 clinical isolates to penicillin and spectinomycin was determined on proteose agar supplemented with haemoglobin and IsoVitaleX in addition to the other two agars (table 2). Once again isolates seemed to be more resistant to penicillin and spectinomycin on GC agar than on DST agar. Proteose agar gave intermediate results.

Table 2 Susceptibility of 100 consecutive clinical isolates of Neisseria gonorrhoeae to penicillin and spectinomycin measured on three different media by agar dilution breakpoint susceptibility testing

\begin{tabular}{|c|c|c|c|}
\hline \multirow[b]{2}{*}{$\begin{array}{l}\text { Susceptibility } \\
\text { category }\end{array}$} & \multicolumn{3}{|c|}{$\begin{array}{l}\text { No of strains in each } \\
\text { susceptibility category }\end{array}$} \\
\hline & $\begin{array}{l}\text { DST } \\
\text { agar }\end{array}$ & $\begin{array}{l}\text { Tested on } \\
\text { proteose } \\
\text { agar }\end{array}$ & $\begin{array}{l}G C \\
\text { agar }\end{array}$ \\
\hline \multicolumn{4}{|l|}{ Penicillin: } \\
\hline $\begin{array}{l}\text { "Sensitive" MIC } \leqslant 0.06 \mathrm{mg} / \mathrm{l} \\
\text { "Intermediate" MIC } 0.12-0.5 \mathrm{mg} / \mathrm{l} \\
\text { "Resistant" MIC } \geqslant 1.0 \mathrm{mg} / \mathrm{l}\end{array}$ & $\begin{array}{r}50 \\
41 \\
9\end{array}$ & $\begin{array}{l}47 \\
42 \\
11\end{array}$ & $\begin{array}{l}42 \\
44 \\
14\end{array}$ \\
\hline \multicolumn{4}{|l|}{ Spectinomycin: } \\
\hline $\mathrm{MIC} \leqslant 16 \mathrm{mg} / 1$ & 68 & 54 & 37 \\
\hline MIC $32 \mathrm{mg} / 1$ & 31 & 45 & 62 \\
\hline MIC $64 \mathrm{mg} / 1$ & 1 & 1 & 1 \\
\hline
\end{tabular}

Table 3 Susceptibility of control strains of Neisseria gonorrhoeae to penicillin and spectinomycin determined on DST, proteose, and GC agars by agar dilution breakpoint susceptibility testing (Figures in parentheses indicate reference laboratory values)

\begin{tabular}{|c|c|c|c|c|c|c|c|c|}
\hline \multirow{2}{*}{\multicolumn{2}{|c|}{ Strain }} & \multicolumn{3}{|c|}{$\begin{array}{l}\text { Penicillin } \\
\text { susceptibility }\end{array}$} & \multicolumn{4}{|c|}{$\begin{array}{l}\text { Spectinomycin } \\
\text { susceptibility (mg/l) }\end{array}$} \\
\hline & & $\begin{array}{l}\text { Teste } \\
\text { DST }\end{array}$ & $\begin{array}{l}\text { Pon } \\
\text { Proteose }\end{array}$ & $G C$ & $\begin{array}{l}\text { Testec } \\
\text { DST }\end{array}$ & $\begin{array}{l}\text { don } \\
\text { Proteose }\end{array}$ & $G C$ & \\
\hline WHO & $\begin{array}{l}\mathbf{A} \\
\mathbf{B} \\
\mathbf{C} \\
\mathbf{D} \\
\mathbf{E}\end{array}$ & $\begin{array}{l}\mathbf{S} \\
\mathbf{S} \\
\mathbf{S} / \mathbf{I} \\
\mathbf{R} \\
\mathbf{R}\end{array}$ & $\begin{array}{l}\mathbf{S} \\
\mathbf{S} \\
\mathbf{I} \\
\mathbf{R} \\
\mathbf{R}\end{array}$ & $\begin{array}{l}S(S) \\
I(I) \\
I \text { (I) } \\
R \text { (R) } \\
R \text { (R) }\end{array}$ & $\begin{array}{l}>64 \\
\leqslant 16 \\
\leqslant 16 \\
\leqslant 16 \\
\leqslant 16\end{array}$ & $\begin{array}{l}>64 \\
\leqslant 16 \\
\leqslant 16 \\
\leqslant 16 \\
\leqslant 16\end{array}$ & $\begin{array}{r}>64 \\
32 \\
\leqslant 16 \\
32 \\
32\end{array}$ & $\begin{array}{r}(128) \\
(16) \\
(16) \\
(16) \\
(16)\end{array}$ \\
\hline $\begin{array}{l}\text { CDC } \\
76-0617\end{array}$ & $\begin{array}{l}\text { F18 } \\
\text { F28 } \\
\text { F45 } \\
782\end{array}$ & $\begin{array}{l}\mathbf{I} \\
\mathbf{S} \\
\mathbf{R} \\
\mathbf{R}\end{array}$ & $\begin{array}{l}\mathbf{I} \\
\mathbf{S} \\
\mathbf{R} \\
\mathbf{R}\end{array}$ & $\begin{array}{l}\mathbf{R}(\mathbf{I}) \\
\mathbf{S}(\mathbf{S}) \\
\mathbf{R}(\mathbf{R}) \\
\mathbf{R}(\mathbf{R})\end{array}$ & $\begin{array}{l}\leqslant 16 \\
>64 \\
\leqslant 16 \\
\leqslant 16\end{array}$ & $\begin{array}{l}\leqslant 16 \\
>64 \\
\leqslant 16 \\
\leqslant 16\end{array}$ & $\begin{array}{r}32 \\
>64 \\
32 \\
32\end{array}$ & $\begin{array}{l}(12) \\
(>32) \\
(12) \\
(12)\end{array}$ \\
\hline
\end{tabular}

Penicillin susceptibility categories:

$\mathrm{S}=$ "sensitive": MIC $\leqslant 0.06 \mathrm{mg} / \mathrm{l}$.

$\mathrm{I}=$ of "intermediate resistance": MIC $0.12-0.5 \mathrm{mg} / \mathrm{l}$.

$R=$ "resistant": $M I C \geqslant 1.0 \mathrm{mg} / \mathrm{l}$.
Table 3 shows the susceptibility to penicillin and spectinomycin of the WHO and CDC control strains determined on GC, DST, and proteose agars, together with their reference laboratory values. (For the WHO strains reference values were determined on Difco blood agar No 5 supplemented with lysed horse blood and an inoculum of $10^{5}$ organisms (personal communication Gonococcal Reference Laboratory, Bristol). The reference laboratory values of the CDC strains were determined on Proteose No 3 agar (Difco) supplemented with $1 \%$ haemoglobin and $1 \%$ IsoVitaleX). We again found discrepancies in susceptibility categorisation-for example, WHO strain B was categorised as "sensitive" on DST and proteose agars but showed "intermediate resistance" on GC agar.

Where discrepancies occurred between the results on different media, isolates always seemed to be more resistant on GC agar than on DST agar. Discrepancies that occurred between breakpoints when comparing GC and proteose agars, and between those when comparing DST and proteose agars, showed no clear pattern.

Table 4 shows the susceptibility to penicillin and spectinomycin of the UKNEQAS strains ${ }^{8}$ determined on GC and DST agars. The reference laboratory values quoted were determined on Oxoid Isosensitest agar supplemented with $5 \%$ chocolated horse blood. With only one exception, results of our susceptibility testing show agreement within a one doubling dilution error of the reference laboratory values. Strain 1312 with a reference laboratory penicillin MIC of $0.03 \mathrm{mg} / 1$ ("sensitive"), was categorised as showing "intermediate resistance". This discrepancy may be due to the use of a different medium for testing together with a one dilution experimental error.

Table 4 Susceptibility of UKNEQAS strains of Neisseria gonorrhoeae to penicillin and spectinomycin determined by agar dilution breakpoint dilution susceptibility testing on DST and GC agars (Figures in parentheses indicate reference laboratory values) $)^{8}$

\begin{tabular}{|c|c|c|c|c|c|}
\hline \multirow[b]{2}{*}{ Strain } & \multicolumn{2}{|c|}{$\begin{array}{l}\text { Penicillin } \\
\text { susceptibility }\end{array}$} & \multicolumn{3}{|c|}{$\begin{array}{l}\text { Spectinomycin } \\
\text { susceptibility (mg/l) }\end{array}$} \\
\hline & $\begin{array}{l}\text { Tested } \\
\text { on DST } \\
\text { agar }\end{array}$ & $\begin{array}{l}G C \\
\text { agar }\end{array}$ & $\begin{array}{l}\text { Tested } \\
\text { on DST } \\
\text { agar }\end{array}$ & $\begin{array}{l}G C \\
\text { agar }\end{array}$ & \\
\hline $\begin{array}{l}1312 \\
1313 \\
1314 \\
1315 \\
1316 \\
1317\end{array}$ & $\begin{array}{l}\mathbf{I} \\
\mathbf{R} \\
\mathbf{R} \\
\mathbf{S} \\
\mathbf{R} \\
\mathbf{I}\end{array}$ & $\begin{array}{l}I(S) \\
R(R) \\
R(R) \\
S(S) \\
R(R) \\
I(I)\end{array}$ & $\begin{array}{r}\leqslant 16 \\
\leqslant 16 \\
\leqslant 16 \\
\leqslant 16 \\
32 \\
\geqslant 64\end{array}$ & $\begin{array}{l}\leqslant 16 \\
\leqslant 16 \\
\leqslant 16 \\
\leqslant 16 \\
32 \\
\geqslant 64\end{array}$ & $\begin{array}{r}(8) \\
(16) \\
(8) \\
(16) \\
(16) \\
(>128)\end{array}$ \\
\hline
\end{tabular}

Penicillin susceptibility categories:

$\mathrm{S}=$ "sensitive": MIC $\leqslant 0.06 \mathrm{mg} / \mathrm{l}$.

$I$ = "intermediate resistance": MIC 0.12 - $0.5 \mathrm{mg} / \mathrm{l}$.

$R=$ "resistant": MIC $\geqslant 1.0 \mathrm{mg} / \mathrm{l}$. 
PRACTICAL CONSIDERATIONS

We found no change in the results of the control strains' susceptibility testing to penicillin and spectinomycin on plates containing antibiotic stored for 10 days at $4^{\circ} \mathrm{C}$ in sealed plastic bags. Hence media could be prepared once a week for the diagnostic laboratory.

Only one or two colonies of an isolate were required to prepare sufficient suspension for inoculating plates containing antibiotic. This allowed susceptibility testing to be started on the morning of isolation when only presumptive identification had been made, and therefore resulted in the unnecessary testing of a small number of pharyngeal meningococci. While growth on DST agar was sufficient to allow end points to be read at 24 hours, the more luxuriant growth on proteose and GC agars made their end points easier to read at this time. A faint haze produced on DST agar, which might be confused with a light growth, was from the inoculum itself. No difference in end point, however, was detected when plates were read at 24 and 48 hours. This resulted in susceptibility results being available at the same time as identification by sugar utilisation tests, producing a minimum delay in reporting to clinicians.

\section{Discussion}

Agar dilution methods have several advantages over disc diffusion methods of susceptibility testing. The antibiotic susceptibility of several organisms may be tested on each plate, the end point is easily read as presence or absence of growth, standardisation of the inoculum is less critical, and reproducibility between laboratories is better. ${ }^{12}$ With disc diffusion methods, inoculum standardisation is more critical and, together with variations in the method of measuring zone size, has been cited as a major cause of interlaboratory variation. ${ }^{1213}$ The UKNEQAS study of susceptibility testing of Neisseria gonorrhoeae ${ }^{8}$ found an association between error rates and the antibiotic content of the discs used. Laboratories using high content tetracycline discs $(25,30$, or $100 \mu \mathrm{g})$ made proportionately more errors than those using low content discs $(2,5$, or $10 \mu \mathrm{g})$. Those laboratories using low content spectinomycin discs (10 or $16 \mu \mathrm{g})$, however, made more errors than those using a higher disc content $(25,30$, or $100 \mu \mathrm{g})$. We have also found no direct correlation between the MIC determined by agar dilution and the size of zone of inhibition of growth in disc diffusion susceptibility tests performed on Neisseria gonorrhoeae (CA Ison and CSF Easmon, unpublished data). The disc method gave larger zones of inhibition of growth of highly sensitive isolates when compared with the zones produced with isolates of reduced susceptibility. Pronounced variation in strain growth rates, however, prevented the use of disc methods to calculate accurately MICs in the manner of the Kirby-Bauer method (Federal Register, 1972, September 30). ${ }^{14}$ Broth dilution methods are unsuitable for the susceptibility testing of gonococci as these organisms grow poorly in liquid media. For these reasons, agar dilution methods are regarded as the most suitable for epidemiological studies of antimicrobial susceptibility. We did not use a full range of antibiotic concentrations as the preparation and inoculation of the large number of plates necessary would have produced an unacceptable increase in workload in the diagnostic laboratory. Instead, we chose breakpoints which produce the most useful results both clinically and epidemiologically. These breakpoints may require revision as changes in antimicrobial resistance occur.

Agar dilution breakpoint susceptibility testing of gonococci is feasible in a routine diagnostic laboratory. In common with the International Collaborative Study, ${ }^{12}$ we found no detectable loss in the antimicrobial activity of plates containing antibiotic stored in sealed bags at $4^{\circ} \mathrm{C}$ for 10 days. This enabled batches of plates to be prepared at the end of one working week for the following week. The ability to read end points at 24 hours rather than 48 hours minimised delays in reporting susceptibilities to clinicians.

The medium used for testing seems to affect the distribution of gonococcal susceptibility to both spectinomycin and penicillin. With the former, changes seen may well have fallen within the limits of experimental error. With penicillin, variation was more definite although not significant. The use of spectinomycin as first line treatment in uncomplicated anogenital gonorrhoea at the Praed Street clinic, prevented us from assessing the clinical importance of strains reported as "sensitive" when tested on one medium but which seemed to be more resistant on another. This would need to be resolved by a large clinical trial. The effect of different media on the in vitro susceptibility of gonococci has also been shown by other workers. ${ }^{14}$ Changes in susceptibility can vary with the antibiotic tested and the media used for testing. For example, Woodford and Ison, working in this laboratory, have shown that isolates may seem to be less susceptible to erythromycin but more susceptible to tetracycline on GC agar than on DST agar. ${ }^{15}$ Unfortunately, at present no internationally accepted method of susceptibility testing gonococci has been agreed. The Centers for Disease Control, Atlanta, which until recently had used Proteose No 3 agar supplemented with haemoglobin and IsoVitaleX, now recommend the use of GC agar with IsoVitaleX for agar dilution susceptibility testing ${ }^{16}$; neither of these media were developed specifically for susceptibility 
testing. The WHO recommends the use of DST agar supplemented with haemoglobin and IsoVitaleX (I Lind, personal communication). We recommend using a defined susceptibility testing medium, and will continue to use DST agar supplemented with lysed blood and IsoVitaleX at present. International agreement on the choice of medium for susceptibility testing Neisseria gonorrhoeae is needed.

The heterogeneity of our population of clinical isolates is indicated by finding $37 \mathrm{~A} / \mathrm{S}$ classes in 100 isolates. Similar heterogeneity has been shown in other populations and has caused concern about how well certain sampling methods represent patterns of antibiotic resistance. Rice $e t$ al found, by using $A / S$ classification, that discontinuous sampling could delay the detection of strains newly introduced into a population or overestimate the importance of transient strains. ${ }^{17}$ They suggested that this problem would not occur if systematic longitudinal sampling was used. Persistent strains would also be readily detected by such sampling.

The methods used in this study could be applied in a routine diagnostic laboratory for immediate clinical benefit and to provide the necessary longitudinal sampling for long term epidemiological studies. To enable direct comparisons to be made between populations at different centres, however, methodology needs to be standardised.

We thank Professor CSF Easmon for his help and advice.

\section{References}

1 Reyn A, Korner B, Bentzon MW. Effect of penicillin, streptomycin and tetracycline on Neisseria gonorrhoeae isolated in 1944 and 1957. British Journal of Venereal Disease 1958;34: 227-39.

2 Dowsett EG. Penicillin resistant gonococci. Lancet 1980;ii:202.

3 Faruki H, Kohnescher RN, McKinney D, Sparling PF. A community based outbreak of infection with penicillin-resistant Neisseria gonorrhoeae not producing penicillinase (chromosomally-mediated resistance). $N$ Engl $J$ Med 1985;313:607-11.

4 Phillips I. Beta-lactamase producing penicillin resistant gonococcus. Lancet 1976;ii:656-7.

5 Ashford WA, Potts DW, Adams HJU, et al. Spectinomycinresistant beta-lactamase producing Neisseria gonorrhoeae. Lancet 1981;ii:1035-7.

6 Easmon CSF, Ison CA, Bellinger CM, Harris JWR. Emergence of resistance after spectinomycin treatment for gonorrhoea due to beta-lactamase producing strain of Neisseria gonorrhoeae. Br Med J 1982;284:1604-5.

7 Knapp JS, Zenilman JM, Biddle JW, et al. Frequency and distribution in the United States of strains of Neisseria gonorrhoeae with plasmid mediated high level resistance to tetracycline. J Infect Dis 1987;155:819-22.

8 Snell JJS, Brown DFJ. Antimicrobial susceptibility testing of Neisseria gonorrhoeae: a trial organised as part of the United Kingdom national external quality assessment scheme for microbiology. J Clin Pathol 1988;41:97-102.

9 Liebowitz LD, Ballard RC, Koornhof HJ. In vitro susceptibility and cross-resistance of South African isolates of Neisseria gonorrhoeae to 14 antimicrobial agents. Antimicrob Agents Chemother 1982;22:598-603.

10 Knapp JS, Tam MR, Nowinski RC, Holmes KK, Sandstrom EG. Serological classification of Neisseria gonorrhoeae with the use of monoclonal antibodies to gonococcal outer membrane Protein I. J Infect Dis 1984;150:44-8.

11 Copley CG, Egglestone SI. Auxotyping of Neisseria gonorrhoeae isolated in the United Kingdom. J Med Microbiol 1983;16: 295-302.

12 Ericsson HM, Sherris JC. Antibiotic sensitivity testing. Report of an International Collaborative Study. Acta Pathol Microbiol B 1971;S217:3-90.

13 Reyn A, Bentzon MW, Ericsson $\mathrm{H}$. Comparative investigation of the sensitivity of N. gonorrhoeae to penicillin. Acta Pathol Microbiol Scand 1963;57:235-55.

14 Dillon JR, Tostowaryk W, Pauze M. Effects of different media and methods of inoculum preparation on results of antimicrobial susceptibility testing of Neisseria gonorrhoeae. Antimicrob Agents Chemother 1987;31:1744-9.

15 Woodford N, Iso CA. The effect of media on the antimicrobial susceptibility testing of Neisseria gonorrhoeae. J Antimicrob Chemother (in press).

16 Centers for Disease Control. Antibiotic-resistant strains of Neisseria gonorrhoeae. $M M W R$ 1987;36 (suppl No 5S): 1S-18S.

17 Rice RJ, Hook III EW, Holmes KK, Knapp JS. Evaluation of sampling methods for surveillance of Neisseria gonorrhoeae strain populations. In Poolman J, et al eds. Gonococci and meningococci. Dordrecht: Kluwer, 1988:164-74.

Requests for reprints to: Dr CA Ison, Department of Medical Microbiology, Wright-Fleming Institute, St Mary's Hospital Medical School, Norfolk Place, London W2 1PG, England. 